\title{
When the Sea meets City: Transformation towards a Smart Sea in Finland
}

\author{
Vaida Meškauskienè \\ Åbo Akademi University \\ vaida.meskauskiene@abo.fi
}

\author{
Anssi Öörni \\ Åbo Akademi University \\ aoorni@abo.fi
}

\author{
Anna Sell \\ Åbo Akademi University \\ anna.sell@abo.fi
}

\begin{abstract}
The Baltic Sea is increasingly becoming a living laboratory for rapid prototyping and testing solutions from cleaner and safer shipping to remote and autonomous navigation. The maritime industry in Finland is rapidly undergoing digital transformation to make activities at sea smarter. A Smart Sea can be understood as an ecosystem across city and sea interface in which businesses, knowledge institutions, citizens, municipal agencies and government collaborate towards shared situational awareness and create value in multiple dimensions - economic, social and environmental. This article presents Smart Sea implementation journey in Finnish public sector through notable improvements and setbacks, and identifies larger transformation effects for the society.
\end{abstract}

\section{Introduction}

Since the earliest representation of a ship under sail found in Kuwait dating to the late 5th millennium $\mathrm{BC}$ [1] and throughout the history, the sea has played a critical role in the development of our civilization, providing humanity with more mobility than travel over land for trade, transport, fishing, and warfare. We are living in one of the most dynamic yet least discussed periods of maritime history as seafaring is rapidly undergoing digital transformation. The maritime industry is fostering globalization and cross-cultural interdependence as it has for millennia but on a much greater scale - one container ship can carry as much load as was moved in a year across the Mediterranean in ancient times [2]. Thousands of containers are loaded on to ships with the assistance of complex algorithms while shipping vessels require a tiny workforce. New generations of cruise ships resemble floating cities rather than vessels [3], and with annual increase in sea cruises and the proliferation of leisure sailing activities at sea a pleasure is made out of what was once a peril. Some 90 per cent of the world's freight is still sea-borne and maritime is fundamental to World economy [4].
All that said, it is well known that the maritime industry has historically been slow to implement new technologies. It is now 30 years behind the technology curve, as many developments maritime companies are working on today other industries have had since the mid-1990s [5]. Perhaps because of its status as a tradition-bound industry, maritime hasn't received sufficient attention from the research community, which has created a gap between the rich innovation literature on ICT and other high-tech industries and a lack of studies on innovation activities in the maritime industry. As an analogue, "We know more about the surface of the Moon and about Mars than we do about [the deep sea floor][6]"- marine biologist Paul V. R. Snelgrove summed up 10 years of studies by a global network of researchers in more than 80 nations. Maritime is one of the most conservative industries, known for its prevailing old culture, dislike towards derailing the traditional norms, lack of collaboration and transparency. This is all about to change soon, with the advent of smart computing (increasing digital connectivity, intelligence) and smart governance at sea.

In this study, we analyze Finnish government innovation initiatives to make activities at sea smart, which are noteworthy efforts for few reasons. The Baltic Sea is one of the world's busiest shipping routes with around 2,000 vessels at sea at any time and the Nordic countries importing 0.4 tones more goods per capita by sea on an annual basis than Japan. For this reason, wellmaintained waterway and smooth logistics are vital, particularly to the countries in the north of the Baltic Sea region [7]. Baltic sea region is a world-leading performer in maritime technology development and became a pilot region for inventing and testing solutions for cleaner shipping and different areas of the Blue Growth economy. In2005 IMO Resolution MEPC.136(53) declared the Baltic Sea a particularly sensitive sea area to protect its unique and sensitive brackish-water ecosystem from international shipping activities and became home to some of the strictest environmental regulations for shipping. Since early 2015, Baltic Sea countries began to electrify its coastal vessels led by Norway, followed by Sweden, Denmark, and Finland. The Baltic Sea is increasingly becoming a living laboratory for rapid prototyping and testing of 
remote navigation and autonomous solutions. Trondheim Fjord in Norway is the first place in the world to be designated for the testing of autonomous ships, while the world's first autonomous maritime ecosystem, One Sea, hosts a $127 \mathrm{~km}^{2}$ test area named Jaakonmeri, located off the west coast of Finland, and open to all organizations wishing to test autonomous maritime traffic, vessels, or technology [8]. The Smart Sea is a rapidly emerging phenomenon in practice, yet undefined in literature. To date there are no evident steps or mechanisms to follow in this technological transition process, neither is it clear what kind of transformational effects it will have on the wider society beyond the improvements in governance and service performance. Technological transitions (TT) are defined as major technological transformations in the way societal functions, such as seaborne transportation, are performed [9]. TT constitutes change from one sociotechnical configuration to another and involves placing new technologies into practice and use through revised regulation, new infrastructure, maintenance network, user practices and culture. Increasingly among researchers, there is a recognition that context has an impact, both directly on innovation determinants, processes, and outcomes, and indirectly through organizational features such as the amount of organizational resources and organizational strategy [10], [11], [9]. Terms "creative destruction" and "new knowledge combinations" are one of the most cited definitions offered by the economist J. Schumpeter [12] to characterize the fundamentals of innovations. In the fusion model presented by Holt [13], an innovation is a synthesis of perceived user needs and recognized technological opportunities for the fulfillment of those needs. Based on these conceptualizations we shape the innovation management concept in this paper under TT umbrella, as analysis and synthesis of knowledge. What makes this research setting particularly interesting and unique is that Finnish transition towards Smart Sea takes place in a multidimensional context, where government is set to play a major role. Finland is a maritime nation and maritime industry is one of the key industries of the country with hundreds of diverse actors in all global market segments of seafaring and ship building. A high proportion of country's foreign trade is carried by sea (about 90\% of its exports and 80\% of its imports) [7], which is vital for the competitiveness of Finland's businesses and for the Finnish society in general. Therefore, it is essential that sea routes are wellfunctioning all year round, reliable, safe and environmentally friendly. Moreover, context for public sector innovation is characterized by large degree of complexity as it is always embedded in society: it is obliged to not only produce innovation in services, but also create changes in regulations, collective rules and user practices, infrastructure, and culture. Uncertainty of the innovation process and its outcomes as well as complexity of innovations and diversity of actors involved are key dimensions for public service organization often seen as resistant to significant innovation. However, Finland as a nation has a long record of accomplishment in adopting innovative solutions to address complex challenges it has faced throughout its history. To continue its proactive approach in dealing with strategic objectives and fulfilling the nation's ambitious goals of becoming a global pioneer in maritime digitalization it has tried to paid significant attention to smarter government [14], i.e. by leveraging proactive and forward thinking approach to the use and integration of information, technology and innovation in the activities of governing.

Smart Sea, as a phenomenon of technological transformation and as a subject of this study, is also set within other dimensions, perspectives and literatures, most prominently those of smart cities. The objectives for the paper are: (1) to carry out a literature-driven discussion on the smart sea concept, and (2) present a case study on an emerging smart sea ecosystem in the Finnish context. The research paper also illuminates on drivers fostering innovation activities at sea, proposes a definition for Smart Sea, explains implementation process that supports innovation journey in public sector through notable improvements and setbacks, and identifies larger transformation effects for the society.

\section{Drivers towards Smarter Sea}

Trends and socio-technical drivers always influence the TT and it has been reflected through history in the city waterfront.

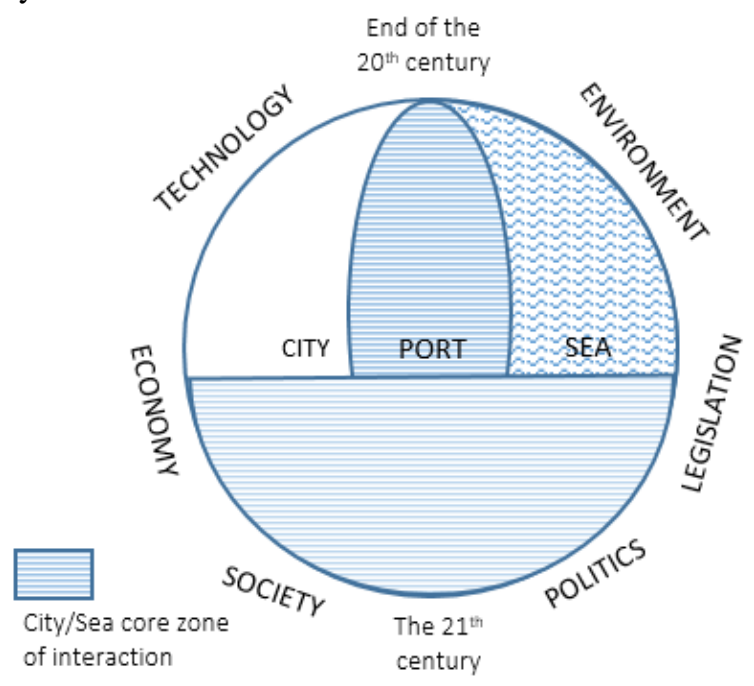

Fig.1.Drivers in the city - sea interface 
By the end of 20th century, maritime industry, 'that once employed vast numbers on land and shore and which had a visible, raucous presence in the heart of major coastal cities has been banished from congested centers' [2], started to feel the outcomes of stagnation. It was very isolated, disconnected, inward looking, and lacking competitiveness.

Technology. Only a small fraction of data could be transmitted over long geographical distances and establishing reliable connectivity at the sea has been challenging until very recently. Improved quality, decreased cost of connectivity between offshore and land opens up wide opportunities for developing big data, industrial internet, automation and autonomous solutions tailored for the sea environment.

Economic drivers. Automation is the main driver in most industries, replacing manpower with machines. Commercial vessels today employ far less personnel than before, so the cost reduction would not be terrific. However, in the long run, the savings would accumulate through better utilization of information for process and fuel optimization. Resource constrained governments seek for smarter provisioning of public services. Ecommerce increases the importance of speed and consumers demand transparency in supply chain.

Society. Collaborative economics, citizenship engagement initiatives provide more participatory options for public innovation. Citizen's opinion matters more than decades ago regarding pollutions in cities and seas driving responsible utilization of natural resources. Maritime industry is worried that it will face tightening labor market with recurrent shortages for experienced officers. Being considered as 'unattractive' industry for young and tech savvy generations is a threat that can be overcome with digitalization of the sector. Improving working conditions for seafarers and reducing safety risks associated with human error is another driver for autonomy in maritime.

Politics. For 'island' nations such as Finland and other Nordic countries, maritime industry is a significant source of economic prosperity. Economic changes, such as prolonged financial crises also affect political processes. In several Nordic countries, maritime digitalization programs became a matter of national strategic priority with dedicated innovation funding, also recognized by EU programs.

Legislation. Intensification of maritime activities create significant pressure on fragile sea ecosystems. Strict regulations in place in Baltic sea region force companies to embrace new solutions for cleaner shipping at faster pace.

Environment. That cities strive to be more livable, environmentally friendly, and cautious about consuming resources and causing traffic pollution, has strong effect on maritime sector. While requirements for energy efficiency and emission control of vessels increase, search for alternative energy sources open up possibilities for blue growth, such as offshore wind.

Interface between the sea and the city is expanding and there is a lot to be learned from smart cities evolution that started a decade ago. Smarter maritime industry means not being left behind in isolation but evolving into a connected, transparent ecosystem with forward looking approach, and that requires smart government facilitation.

\section{Conceptual debates in literature}

\subsection{Key similarities between the smart city and the smart sea}

Smart Sea, as a new phenomenon and the focus of this study, is set within the well-established literature of the smart city. Key characteristics that make seas smart seem to follow in the footsteps of the smart city movement, which seems to have completed its hype cycle recently. The smart city related research generated key definitions and a consensus on fundamental elements of the smart city [15], [14], [16], [17]: governance, commons, technology, and digital infrastructure. In line with this broader definition, cities can become smarter "... when investments in human and social capital and traditional (transport) and modern (ICT) infrastructure fuel sustainable economic growth and a high quality of life, with a wise management of natural resources, through participatory governance" [18]. Most authors consider ICT innovations in technology to be at the core of the smart city concept [15], [19], [17] and foundational principles for instrumented, interconnected and intelligent city "connecting the physical infrastructure, the IT infrastructure, the social infrastructure, and the business infrastructure to leverage the collective intelligence of the city'[20]. Technology contributes to the planning and management of cities, generating big data that provide real time awareness of the real world [15], [21],[20]. Rapidly developing 4G/LTE networks, satellite communication allows greater connectivity at sea, while miniaturization of components with their unique IP-address, affordability of sensors and IOT devices facilitate extensive monitoring of waterway infrastructures and vessel operations. Similarly, to smart cities, focus at sea is gradually shifting from hardware to software: services platforms in the cloud are replacing product-based maintenance systems, while vessels and navigational instruments are becoming increasingly software-centric.

Most smart cities as well as smart sea initiatives that leverage modern technology for creation of public value 
are driven by governments, and typically require solid investment, strategic alignment to national policy, and smart government. Scholl and Scholl [19] define elements of smart government as open decision-making, information sharing and use, stakeholder participation and collaboration, improvement in government operations and services, all through the use of intelligent technologies as they facilitate innovation, sustainability, competitiveness, and livability. Finnish governmental agencies responsible for waterways and the legislature have been practicing an early adopter mentality of smart government and favor introduction of novel technologies, deliver more than expected to ameliorate environmental concerns of the Baltic Sea, and take leading positions globally in order to improve regulatory framework under IMO [22]. Gil-Garcia provides perspectives on the nature of smart governments and summarizes its smart initiatives into two categories: on how smart governments are opening up public sector processes and data and transforming service delivery to become smarter [14]. There are key similarities between the smart city and the smart sea (Table 1): smart waterway and maritime traffic innovation initiatives launched during 2016-2018 in Finland involve both opening up public sector data and transforming service delivery through 'open door' innovation programs and public private participation. It is worth noting that novel business innovations and service improvements were rare through open data programs both in the city [16] and sea contexts [23]. Collaborative economy paradigm and growing interest in entrepreneurial innovation is spreading form city initiatives towards seas. In both city and sea context, architecture of collaboration and governance increasingly takes the form of an ecosystem. Based on an analysis of Vienna, London, and Chicago, cities are governed either as "extended enterprises" where inputs from specialized organizations are coordinated and integrated into the final service or as "platform markets" where direct interactions between third-party service providers and citizens are facilitated by the city leaders [24]. Along these lines we identify Finnish waterway ecosystem transitioning towards platform approach as it gradually encourages distributed innovation and, in some cases, does not directly procure the activities. While OneSea ecosystem resembles today an extended enterprise model it is in its beginning as the digital infrastructure has not yet been developed for autonomous vessels. If smart cities are viewed as the "ecosystem of ecosystems," where governance leaders choose the appropriate structure and manage the ecosystem dynamically [24], then this can be applicable to smart seas as the different ecosystems have complex network or multiple stakeholders, multiple interlinked goals, common long-term vision and different maturity level of infrastructure (Figure 2). In these ecosystems, both commons (collectively shared resources, knowledge, databases) and digital infrastructures (protocols, processes, systems that connect actors) are basic elements [16],[25],[26]. Successful smart cities collaborate across sector boundaries with diverse partners from industry and academia bringing creativity and capabilities that most governments lack [16]. It is argued that collaboration between these actors, known as the "triple helix" [27], strongly influences smartness of a city [28] and has historically proven crucial also for the success of large-scale maritime innovation projects.

Table 1. Key similarities and differences between the smart city and the smart sea

\begin{tabular}{c} 
Similarities \\
\hline Smart Government and transparency initiatives \\
\hline Governance, commons, digital infrastructure, technology \\
\hline Ecosystem as a governance approach \\
\hline Growing interest in entrepreneurial innovation \\
"Triple helix" model applied for collaboration \\
"Triple bottom line" as value drivers of smart growth \\
Differences
\end{tabular}

\section{Differences}

The sea is isolated, tough environment to innovate: predictability, durability, reliability issues

Conservative $\&$ safety culture of maritime creates resistance Slow TT, adoption of innovation due to international regulation Small potential market of smart sea fails to attract innovators Knowledge gap between Marine and ICT - barrier to innovate

Our review of literature suggests that at the intersection of social, environmental and economic performance, there are activities that smart cities engage, which not only positively affect natural environment, wellbeing, livability of society and publicsafety, but also result in longer-term economic benefits and competitive advantage for the city. Value drivers of smart cities link historically to the American sustainability concept "Smart Growth". This perspective also corresponds to the idea of the triple bottom line, a concept developed by Elkington [29], which simultaneously considers and balances economic, environmental, and social goals from microeconomic standpoint. Sustainability is now a fundamental principle of smart management [30] and also a matter of growth for smart sea ecosystems and businesses involved in maritime digitalization activities. In the next Industrial revolution, the future of smart seas, as well as cities lies in building sustainable economic reality that connects industry, society and the environment [31]. As P. Senge sums up, epochs in human history that have nurtured all three Worldviews (rationalism, naturalism and humanism), have stood out as golden ages. 


\subsection{Key differences between the smart city and the smart sea}

It is easier for radical innovations to break through in the city context rather than the sea context for several reasons (Table 1). In many aspects, the public sector unit responsible for the smart sea infrastructure is lagging behind any other transport infrastructure units, such as roads and railways, where majority of innovation projects take place in cities. A conservative culture still strongly prevails amongst most experienced leaders with maritime background. The safety has been and still is a challenge in a marine environment, where unpredictable force of nature is always present and cannot be fully controlled. By nature, maritime safety is a very complex issue. Besides policy instruments, such complex issues as language, authority and communication are all determined by individual and institutional relationships. Several studies have pointed out to the safety culture of the maritime industry [32], which is in many ways, old-fashioned: there is a high tolerance for accepting incidents and near misses in the maritime community; mariners are not proactive on safety issues; Pilots and VTS centers cannot command ships, only give advice; it is still the basis of maritime law that the ship master is in absolute charge of his vessel. This practice is at odds with safety cultures of other industries, e.g. aviation, that acknowledge that organizational or industry-wide level hazards are greater causes to accidents than the actions of a single officer on board [33]. The transition typically begins within a small niche market and takes a long time to break through, as it involves selection of dominant design and regulatory approval, which takes years to negotiate internationally. Modifying any regulation in maritime is a broad task because of its global nature: it is always a combination of both natural and international rules, such as IMO. Legislation typically lags behind technology development; especially in maritime any introduction of incremental improvement requires local government and national governmental bodies to break the ice internationally. The TTs in maritime usually last a long period, often decades [9], e.g.: development from sails to steam engines and further to diesel engines, containerization and digitization of nautical charts. Very typical to maritime is that in transition phase the old existing socio-technical regime and new technology with associated infrastructure and regulation co-exist and compete, complicating traffic supervision and situational awareness. Building a new vessel is a capitalintensive undertaking with vessels typically expected to be in use for about 40 years. The sea is also a tough natural environment to innovate as solutions developed for use on land must be adapted to the sea conditions because of durability issues. Maritime is a tough business environment to enter because new technology and equipment needs to be approved and regulated before it can be used at sea, which requires careful investment planning. City and sea infrastructures are confronted with different challenges. While reliability of infrastructure in cities means coping with complex urban environment by building requisite capacity to achieve resilience, at sea the reliability is directly related to public safety, collision avoidance or grounding. Human error is often blamed for accidents at sea and is the target to be eliminated by digitalization. It is also easier to predict and escape the environmental conditions on land, than sea, which is very dynamic. In terms of value delivered, differences exist particularly in social aspects. Maritime social value is primarily associated with public safety rather than with wellbeing, in contrast with smart cities. Safety driver creates a need for situational awareness systems to be in use and legislation makes it mandatory.

In addition to three other types of actors, defined as "triple helix" model, the role for citizen engagement and civic society is growing in cities yet only moderately in smart sea ecosystems. Smart cities are natural centers of higher education and smart workforce, generating scientific ideas, creativity, and innovation while maritime historically has been focused on voyages, far away from knowledge centers and only sporadically facing port cities. Moreover, maritime-specific domain knowledge, terminology and principles are alien to most of the software developers and act as a barrier to their participation in open innovation, unless they happen to be maritime hobbyists as well. Because maritime knowledge is an isolated area of expertise, the majority of smart sea innovations historically have evolved within quite closed, homogeneous expert communities deeply specializing in maritime technology, which is mostly based on HW development. The maritime industry is at a disadvantage in terms of unit volumes of vessels and navigational aids needed when compared to the automotive sector. The pre-existing knowledge gap together with limited market potential may reduce attractiveness of smart sea initiatives and lead to open calls for innovation not getting the attention they deserved, which weakens the competitive position of the smart sea for knowledgeable suppliers compared to smart cities, most of which are more advanced today in their steps of digitalization. While smart cities are becoming the innovation playgrounds for the booming sharing economy, driven by convergence of numerous factors including the growing environmental consciousness, ubiquity of ICT, the density of economic activity, and housing in urban areas [17], smart seas are still decades behind the trend. The Baltic Sea Cloud could serve as a frontrunner of such an ecosystem, but basics need to be fixed first. Ship connectivity network 
based on satellite and vessel traffic center-based communications are to be enlarged to share information in real time for safety reasons, such as voyages, environmental and bathymetric modelling. The shipping industry, which for a long time has been dark and disconnected, needs to move away from inflexible and inaccurate EDI infrastructure to find common standard for sharing vital shipping information to the end user. Based on conceptual debates in literature, drivers and latest empirical evidence, we propose the following definition: A Smart Sea can be understood as an ecosystem across city and sea interface in which businesses, knowledge institutions, citizens, municipal agencies and government collaborate towards shared situational awareness and create value in multiple dimensions - economic, social and environmental.

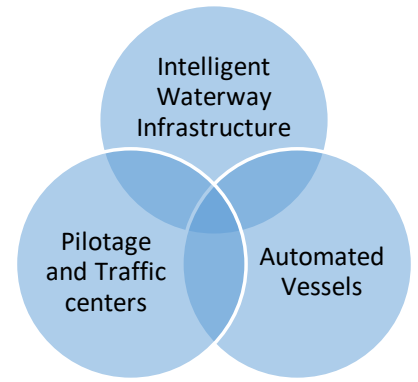

Fig.2. The Smart Sea Ecosystem of Ecosystems

Key ecosystems in the smart sea were identified based on accountability for smarter activities at sea and being the first ones to be fundamentally affected by the digitalization. Their joined ecosystem development activities defined in 'shaded area' that brings together different stakeholder groups of "triple helix".

\section{Smart sea in practice: A case study on Finnish public sector projects}

The ecosystem of Intelligent Waterway Infrastructure is the only one in maritime industry led and orchestrated by Finnish government. It consists of the Ministry of Transportation and Communications (LVM) which deals with matters concerning the safety of waterborne traffic, aids to maritime navigation (ATNs), legal issues concerning shipping and maritime environmental legislation, governmental agencies TAFFI for implementing safety regulations and Finnish Transport Agency (FTA) for maritime affairs. FTA consists of two major functions: marine traffic center (VTS) and waterway infrastructure service (cartography, ATNs, waterway markings and maintenance). Ecosystem also involves 'triple helix' (pilots and master mariners from shipping companies, established incumbents and start-ups, educational institutions, local and international authorities) and has channels to engage citizens: google user group for open data innovation, on-line customer feedback channels.

\subsection{Methodology}

Our study aims to elaborate theoretical concept of smart sea with empirical observations in practice. We investigate the smart sea phenomenon and its implementation process through government innovation programs carried out by FTA for Maritime. Three different coastal areas in Finland have been involved in the digitalization experiments: Färjsund, Rauma, Pyhäranta. These and local players, such as marine pilots, maintenance people, ports, municipalities and local recreational boaters had opportunity to form early experiences on what the smart fairways will be and raise concerns on how it will affect them in the future. The research is based on ethnographic observations and 69 in-depths interviews conducted in 2017-2018. It involves municipal and local officials, business representatives from large and small companies, leaders and public figures from different associations and One Sea ecosystem, lecturers, researchers, students and startup developers in the Maritime industry Cluster. Additionally, the following archival data has been used in the research: project documentation, posts in discussion forums, communication material on company websites, press releases, critical incidents/technical failure reports, measures/KPIs of success, annual reports, strategy documents, policy briefings. In specific, we aim to answer these questions: (1) what digitalization means to your organization and what drives it? (2) How do you make it happen? (3) What are the key issues and outcomes in the implementation process? As our research subject is new one, we attempt to generate new theory on the basis of existing constructs. Therefore, a case study research is chosen, which is generally recommended as a suitable research design for theory building [34],[35]. Employing action research design allows us to intimately connect with the empirical reality of maritime industry and employ hands-on approach [36], which is often problematic for outside researchers. In maritime industry, the content matter tends to be complicated by the complexity of domain specific knowledge and number of stakeholders involved from different ecosystems. The researcher has been actively involved in the digitalization of sea infrastructure projects for the period of about 1,5 years. Besides the possibility to closely observe organization, an action research approach has other well-noted advantages: it enables researcher to revisit the organization after they are no longer involved directly in the project, and ensure the research results will be of guaranteed practical relevance [37]. 


\subsection{Implementing smart sea infrastructure}

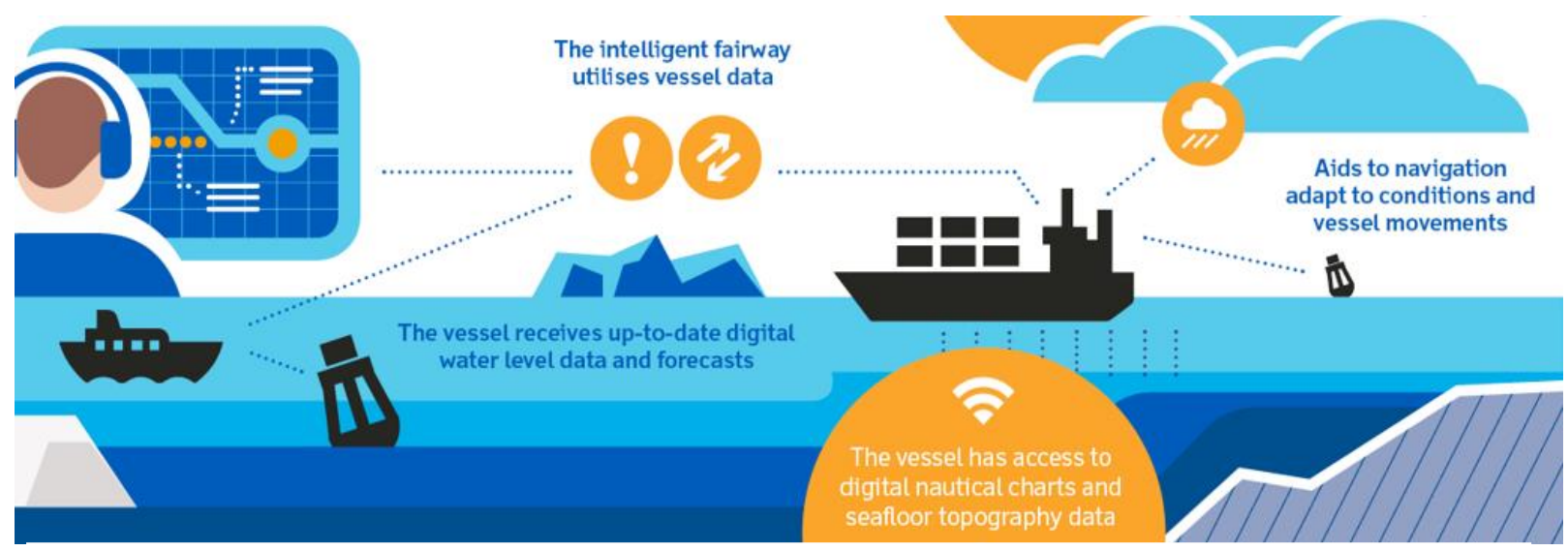

Fig.3. Smart Sea projects in waterway infrastructure ecosystem in Finland (Source FTA 2016-2018)

Following the strategic research agenda for the Finnish smart maritime technology solutions by 2025 [22], the LVM started initiatives aiming to not only transform maritime sector to the digital age but direct all its activities to place Finland in the leading role of digital maritime technology. Anne Berner, Minister of Transport \& Communications of Finland highlighted that "Finland is a forerunner of digital vessel services. Intelligent automation in fairways is the key to enhancing maritime safety, reducing emissions, and improving productivity". Along these lines in 2016, the FTA launched a set of intelligent waterways projects to meet the future needs of commercial shipping, results from which would be also used for future requirements and opportunities for developing remote and autonomous navigation. The Intelligent Fairways project called for innovative solutions that will improve the cost effectiveness of transport, make route planning and navigation easier, lower the risk of collision, reduce the number of vessels running around and reduce the probability of environmental damage. The project scope varied from developing depth models, water level data and water level forecasts, which will help optimize transport in accordance with the prevailing conditions, to developing collection and distribution of water level and weather data using AIS and exchange of vessels routes with VTS. Still others aimed at developing remote control solutions for aids to navigation, up-todate and reliable navigational and hydrographic data standardized nautical charts, efficiency in maintenance services - criteria that play a key role in digitalization projects ensuring the functionality and safety of vessel traffic. Implementing incremental or radical solutions at sea cannot be a random activity. Digitalizing maritime activities is a gradual, phased process, with experimental learnings and adjustments along the way. Our analyzed projects suggest that any innovation should follow certain steps along the implementation process, starting with its inception at transparency phase and all the way aiming to reach shared situational awareness for all the actors working at sea, either presently or remotely.

Transparency of the FTA processes and data has been one of the most important enablers of expansive use of digitalization and experimental service innovations aimed at supporting value creation for society. Transparency is defined as "the perceived quality of intentionally shared information from a sender" [38]. To increase transparency, organizations should actively infuse greater disclosure, clarity, and accuracy into their communications with stakeholders. A transparent organization provides information in such a way that the stakeholders involved can obtain a proper insight into the issues that are relevant for them and implies openness, communication, and accountability. In 2016 FTA kick started maritime digitalization through transparency initiatives in two ways: (1) by embracing so called 'Open Door' approach through open public innovation calls to streamline operational efficiency of waterway services and (2) by opening data from public authorities to stimulate creation of new software applications, digital service offerings and added value for businesses and citizens. Instrumentation is a central characteristic of making seas smarter. We rely on the following definition from smart city context: it enables the capture and integration of real-world data in nearreal-time through the use of both physical (sensors, cameras, smart phones) and virtual sensors (the web, other similar data-acquisition systems, including social networks as networks of human sensors) [20]. Interconnection means the integration of those data into an enterprise-computing platform and the communication of such information among the various city services. Intelligence extends the process of smart sea implementation and refers to the inclusion of complex analytics, modeling, optimization, and 
visualization in the operational business processes to make better operational decisions [20]. For maintenance teams, the key objective is to ensure safety of fairway infrastructure and navigational aids, which involves constantly building situational awareness over large volume of space and sharing it within own organization, VTS, mariners and public. For the pilots on a manned ship bridge and traffic center operators key work activities evolve around constantly building and retaining situational awareness. The term situational awareness is defined as "The perception of elements in the environment within a volume of time and space, the comprehension of their meaning and the projection of their status in the near future" [39]. Instrumentation through IOT sensors, followed by integration of data into common cloud with computational intelligence will create different models and project scenarios. For service technicians, this will lead to enhanced situation awareness in waterways in near real time. When it is shared with VTS operators and pilots, it will bring every actor at the same level of situational awareness and will increase collaboration, safety, and lead to increased transparency, especially critical when solving unexpected problems. This will trigger another loop of implementing smart solutions at sea. All successfully completed projects under waterway digitalization initiative deliver value in multiple dimensions of sustainability to some degree: economic, environmental and social. As benefits in early phases of smart waterway initiatives will fuel the scale of digitalization of the smart infrastructure, it will result in more automation, and less human presence at sea will be required to ensure safety. In fact, our analysis of smart sea waterway projects indicates that in order to capture full economic benefits of digitalization, would the physical presence of professionals at sea should be kept to a minimum, and ideally only as the last resort option for instances when the technology fails.

\subsection{Lessons learned}

Maritime in Finland has a long way to go before the system fully transforms into the smart digital sea. We uncovered several setbacks for implementing innovations towards smart sea and group them into two categories: (1) coming up with innovations and (2) placing innovation into practice. The latter is related to adoption of innovation, where governmental efforts fail due to these reasons: a combination of conservative, safety driven culture that often is accompanied by resistance to change, and complex international regulation, which slows diffusion and prevents adoption of innovation. The former group of obstacles is hindering innovation management: existing knowledge gap between Marine and ICT, the small potential market, poor availability of commons in the smart sea ecosystem (shared knowledge, database, co-working space, access to external knowledge) and lack of active management of required competence and cross sectoral knowledge exchange and combination. The maritime ecosystem did not transform into smart sea because there was a lack of innovation due to absence of knowledge synthesis. It proved to be more complex to carry out interconnection and intelligence steps in waterway innovation projects than in any other traditional markets. Because maritime knowledge is an isolated area of expertise, the majority of smart sea innovations projects have been implemented by a relatively closed, historically homogeneous expert community of private companies, research institutes and public agencies, deeply specializing in maritime technology that was predominantly based on HW development. Digitalization challenged prevailing skillset of homogeneous smart sea ecosystem. Skills, such as advanced software knowledge in geographical information systems, machine learning and computer vision are in obvious shortage in the existing community of companies that supply innovations and have historically been excelling at delivering HW instrumentation, and this shortage became a showstopper in the most radical innovation projects. On the other hand, innovating in smart sea requires at least a basic skillset of maritime specific knowledge and familiarity with definitions, something that is not traditionally present in software developers, except in the tiny minority who happen to be maritime enthusiasts or with relevant master marine education. Naturally, this isolates larger proportion of Finnish developers, who would have been invaluable in delivering wide range of applications for FTA and the wider community. The pre-existing knowledge gap reduced attractiveness of smart sea initiatives, and open calls for innovation did not get the attention they deserved. The gap also weakens smart sea ecosystems' competitive position for knowledgeable suppliers against urban industries, most of which are more ahead today in their steps of digitalization. This could have been easily avoided with on-line training, educational seminars, info-sessions and communicating guidance on policy briefings as well as actively sharing insights on the key operational challenges facing the infrastructure. Unlike in smart city context, the innovation process in smart sea ecosystem needs to be managed differently. As our case study shows, innovation conception in smart sea context has to be more actively managed by placing special attention to internal and external knowledge synthesis across the sectors. In smart cities, the knowledge synthesis is automatically generated by its members, who live there, are active users of city services and have a profession. This dual role provides citizens with tools 
to innovate. However, most of us are neither mariners, nor ICT professionals and automatically we have nothing to give to the smart sea.

Smart government initiatives in maritime are complex and cuts across functions and sectors. Only senior leaders can orchestrate such a complex system and, as quoted by J. P. Kotter, would dare "to make the status quo seem more dangerous than launching into the unknown" [40]. Government officials have identified both transparency initiatives and the public crowdsourcing as potential threat to navigational safety. This reasoning is deeply rooted in the traditional maritime culture where historically any introduction of incremental innovation in maritime (such as new navigational instruments, processes or vessels) placed safety first into the equation of potential benefits. The safety has been and is a challenge in a marine environment, where unpredictable force of nature is always present and cannot be controlled $100 \%$. Therefore, conservative culture still strongly prevails amongst most experienced, leading officials in the public sector unit of waterway and marine traffic: any introduction of a new is a risk to public safety. The issue of talent gap also relates to a lack of visionary and committed leadership. It's far easier to introduce bottom-up innovation and implement change if you have around people equipped with the right competences, who also have a pulse on technology and positive believe it can benefit the society at large.

Ever expanding interface and intensifying innovation activities between smart city and smart sea creates perfect environment for collision of maritime and IT knowledge. As a result, we will likely see the profession of mariners being increasingly digitalized and a growing number of 'digital captains' and remote maintenance operators, who will require machine learning, big data analytics and visualization skills to start with. This creates a need for the 'Marintech' profession - still a challenging job, but based in cities rather than at sea, and most likely to appeal to passionate mariners with nautical background and forward-looking digital competences.

\section{Conclusions}

At the moment digital revolution is hitting the sea. The smart sea movement is slowly emerging with vibrant innovations being delivered both offshore and ashore, and major transformations expected to happen in maritime industry. We might restore the splendor of the seas and prosperity of maritime industry through smarter management of our resources and information, and with the latest technological innovations undoubtedly aiding along the way. Smart government is tapping into the creative talent of ICT communities and digital competence of companies in smart cities to transform waterway infrastructures. Innovative tools and systems are enabling vessel operators to make smart decisions and helping them stay competitive in today's market. Remote pilotage, vessel maintenance and waterway infrastructure functions are undergoing a major digitalization phase, as described in our case study, which can transform service delivery toward a safer, more efficient and environmentally friendlier way. Alongside the immediate improvements, some unexpected outcomes occur, such as innovation management failures, shifting work practices and routines from shore to city and the redefinition of the mariner's profession. A traditional mariner's profession, which is typically characterized by work taking place far away from the busy city life in remote areas of the sea and under challenging environmental conditions, is being moved from offshore to the city, where it becomes an office job, a computer window projecting the status at sea and tools for remote navigation. One element that maritime TT will affect the most is the established mariner practices, skills and routines at sea. The majority of those to be affected either do not believe such a change is coming or have some erroneous beliefs about those changes not happening, technology most likely failing, or that the transformation is not going to affect them. One of the negative side effects of the TT in the long run is the gradual elimination of mariners' presence at sea, which was the main reason why they obtained the profession in the first place. The impact for society means there will be no need for professionals working at sea, apart from the rare cases of emergency and leisure. Instead, an ever-expanding interface between the city and the sea will blur the intersection of maritime and IT knowledge, which will create the need for a new breed of 'Marintech' professionals in the very near future. This knowledge synthesis can make maritime industry a lot more attractive to the future generations, however it does not happen automatically in smart sea context and needs to be actively managed by public authorities.

Maritime culture will open up for the digital change if the affected people can be convinced the mariners are needed to supervise increasingly automated activities of the smart sea and that their knowledge is here to stay in the digital $21^{\text {st }}$ century. It may be essential to keep up the traditional maritime navigation knowledge to a certain degree for emergencies that may strike in the form of blackouts, natural disasters or cybercrimes. Mariners who, as L. Paine points out, have "fostered cross-cultural interdependence" throughout human history [2], will continue to play an important role in defining the technological transition of maritime by learning, adjusting, and selecting radically new 
technologies that work and can become a part of their new routines.

\section{References}

[1] R. Carter, "Boat remains and maritime trade in the Persian Gulf during the sixth and fifth millennia BC," Antiquity., March 2006.

[2] L. Paine, The Sea and Civilization: A Maritime History of the World, New York: Alfred A. Knopf, pp.744, 2013.

[3] "cruiseline.com".Available:https://cruiseline.com/advice/ cruising-101/all-about-cruising/cruise-ships-of-the-future.

[4] "IMO (International Maritime Organization), UN," [Online]. Available: https://business.un.org/en/entities/13.

[5] M. C. Forum, March 2018.Available: https://splash247.com/maritime-ceo-forum-shippinganywhere-30-500-years-behind-technology-curve/.

[6] P. Snelgrove, Discoveries of the Census of Marine Life: Making Ocean Life Count, Cambridge University Press, 2015. [7] K. Liuhtio, et al, "The maritime cluster in the Baltic Sea region and beyond: BSR Policy Briefing 1/2016," Centrum Balticum Foundation, 18.5.2016.

[8] "businessfinland.fi".Available:https://www.businessfinlan d.fi/en/whats-new/news/2018/finland-takes-the-lead-indeveloping-maritime-digitalization-and-autonomousshipping/.

[9] F. Geels, "Technological Transitions as evolutionary reconfiguration processes: amulti-level perspective and casestudy,"Reserach Policy, vol.31, pp. 1257-1274, 2002.

[10] J. Hartely, "Innovation in Governance and Public Services: Past and Present," Public Money and Management, 25:1, 27-34, 2005.

[11] J. Tidd, " Innovation management in context: Environment, organization and performance.," International Journal of Management Reviews, 3, pp. 169-183., 2001. [12] J. Schumpeter, The theory of economic development, MA: Harvard., 1934(new edn 1961 ed.).

[13] K. Holt, "Generating creativity, ideas and inventions: Information and needs analysis in idea generation," Research Management, 18(3), 24-27., 1975.

[14] J.L.Gil-Garcia, N. Helbig, A. Ojo, "Being smart: Emerging technologies and innovation in the public sector," Government Information Quarterly, vol. 31(2014)11-I8. [15] H. Chourabi et al., "Understanding Smart Cities: An Integrative Framework," HICSS, 45th Hawaii International Conference on System Science (HICSS), IEEE, 2012.

[16] E. Almirall, et al.,"Smart Cities at the crossroads: New Tensions in City Transformation", California Management Review, Special Issue on City Innovation, 2016, Vol. 59(1) 141-152.

[17] B. Cohen, E. Almirall, H.Chesbrough."The City as a Lab: Open Innovation meets Collaborative Economy," California Management Review, Special Issue on City Innovation, 2016, Vol. 59(1) 5-13.

[18] A. Caragliu, C.D. Bo \& P. Nijkamp, "“Smart Cities in Europe."," Journal of Urban Technology 18 (2): 65-82., 2011. [19] Scholl, H. J. \& Scholl, M. C. "Smart Governance: A Roadmap for Research and Practice". In iConference 2014 Proceedings. Berlin, Germany, March 4-7, 2014, 163-176.
[20] C. Harrison, et al., "Foundations for Smarter Cities," IBM Journal of Research and Development, 54(4), 2010.

[21] M. Batty, et al., "Smart Cities of the Future.," UCL Centre for Advanced Spatial Analysis, Paper.

[22] Ministry of Economic Affairs \& Employment of Finland, "Smart maritime technology solutions. A Strategic Research Agenda For The Finnish Maritime Cluster 2017-2025". [23] Ministry of Finance, "The impact of open data- a preliminary study," Ministry of Finance Publications, Finland, $15 \mathrm{~b} / 2015$.

[24] I.Visnjic, et al., "Governing the City:Unleashing Value from Business Ecosystem," California Management Review, 2016, Vol. 59(1) 109-140.

[25] C.C. Snow, D.D. Håkonsson \& B.Obel. "A Smart City Is a Collaborative Community: Lessons from Smart Aarhus," California Management Review, 2016, Vol. 59(1) 92-108. [26] J. Wareham, P.Fox \& J.Cano."Technology Ecosystem Governance,"Organisational Science, vol.25/4,pp.1195-1215, 2014.

[27] K. Kourtit, et al., "An Advanced Triple Helix Network Framework for Smart Cities Performance," in Smart Cities Governing, Modelling and Analysing the Transition, edited by M. Deakin, 196-216., New York: Routledge., 2015.

[28] P.Lombardi, et al., "Modelling the Smart City

Performance, Innovation," Innovation: The European Journal of Social Science Research 25 (2): 137-149., 2012.

[29] J. Elkington. Cannibals with Forks: The Tripple Bottom Line of the 21 st Century. New Society Publishers, Stoney Creek,CT, 1998.

[30] A. Savitz \& K.Weber. The Tripple Bottom Line,, JosseyBass, San francisco, CA, 2006.

[31] P.M. Senge, and G. Carstedt, "Innovating out Way to the Next Industrial Revolution," MIT Sloan Management review, vol. Winter 2001, pp. 24-38, 2001.

[32] J.Lappalainen, "Transforming maritime safety culture evaluation of the impacts of the ISM Code on maritime safety culture in Finland",University of Turku, A46, 2008

[33] J.Kuronen, U.Tapaninen, "Maritime safety in the gulf of Finland", Center for Maritime S., University of Turku, 2009.

[34] Eisenhardt, K."Building theories from case study research," Academy of Management Review, 14(4)(1989), pp.532-550, 1989.

[35] R.Yin, Case Study Research:Design \& Methods, 1989. [36] P.Reason, H.Bradbury, Handbook of Action Research: Participative Inquiry \& Practice, Sage, London, 2000.

[37] J. Gill, Research as action: An experiment in utilising the social sciences. F. Heller (Ed.), The Use and Abuse of Social Science, Sage, London, 1983.

[38] A.K. Schnackenberg \& E.C. Tomlison,"Organizational Transparency: A New Perspective on Managing Trust in Organization-Stakeholder Relationships," Journal of Management, Vol. 42 No. 7, November 2016.

[39] M.R. Endsley. "Design and evaluation for situation awareness enhancement," Proceedings of The Human Factors Society 32nd Annual Meeting, 1988.

[40] J.P.Kotter, "Leading Change: Why Transformation Efforts Fail," Harvard Business Review, March-April, 1995. 